\title{
LAS PLANTAS CANTAN EN EL JARDÍN: LA CONSTITUCIÓN DE UNA RETÓRICA VEGETAL Y UNA SUBJETIVIDAD NÓMADE ECOLÓGICA EN EL POEMARIO EL JARDÍN (1992), DE DIANA BELLESSI ${ }^{1}$
}

\author{
Ignacio Sánchez Osores \\ Pontificia Universidad Católica de Chile \\ insanchez@uc.cl \\ Recibido: 11/02/2020 - Aprobado: 21/03/2020 \\ DOI: doi.org/10.17533/udea.lyl.n78a16
}

\begin{abstract}
Resumen: Este artículo plantea que en el poemario El jardín (1992) de la poeta argentina Diana Bellessi se elabora una retórica vegetal a través de las estrategias poéticas del devenir vegetal (Deleuze \& Guattari, 1988) de la voz poética y de los metapoemas que homologan el acto de escribir con el de plantear o jardinear. Mediante estas estrategias la poeta configuró una subjetividad nómade (Braidotti, 2004) ecológica que no solo denuncia la violencia sexo-genérica que se inscribe sobre las mujeres, sino también postula una ecopolítica (Shiva, 1997) que aboga por la convivencia y el respeto de la biodiversidad.

Palabras claves: retórica vegetal; devenir; metapoemas; subjetividad nómade ecológica; ecopolítica.

\section{PLANTS SING IN THE GARDEN: THE CONSTITUTION OF A PLANT RHETORIC AND AN ECOLOGICAL NOMADIC SUBJECTIVITY IN THE POETRY BOOK EL JARDÍN (1992), BY DIANA BELLESSI}

\begin{abstract}
This article states that in the poems El jardin (1992) of the argentine poet Diana Bellessi, a plant rhetoric is elaborated through the poetic strategies of the vegetable becoming (Deleuze \& Guattari, 1988) of the poetic voice and of the metapoems that standardize the act of write with the pose or garden. Through these strategies, the poet configures an ecological nomadic subjectivity (Braidotti, 2004) that not only denounces the sex-generic violence that is registered on women, but also postulates an ecopolitic (Shiva, 1997) that advocates coexistence and respect for biodiversity.
\end{abstract}

Key words: vegetal rhetoric; becoming; metapoems; ecological nomadic subjectivity; ecopolitics.

1. Este artículo se inscribe en el Proyecto Fondecyt Regular $\mathrm{N}^{\circ} 1171337$ Hacer cantar la maravilla: plantas medicinales en cantos rituales, tonadas y poemas de mujeres-Chile-Wallmapu XX-XXI, cuya investigadora responsable es la Dra. Rubí Carreño Bolívar. 


\section{Introducción: Del florero de porcelana a la planta que canta: representaciones y autorrepresentaciones de las mujeres en la poesía latinoamericana}

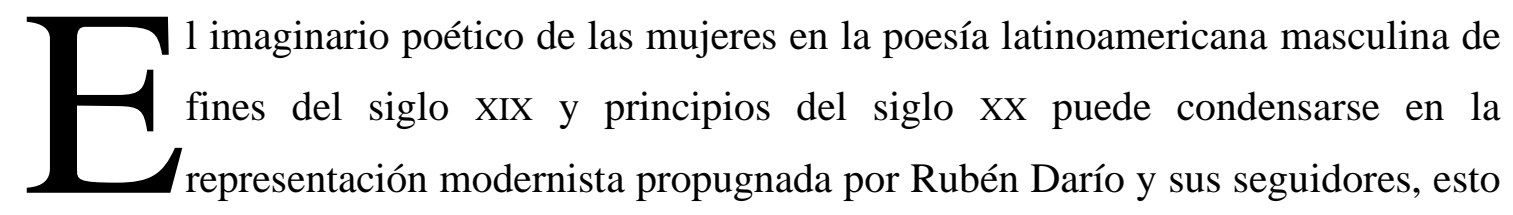
es, la de objeto suntuoso del poeta, a quien se le canta y convierte en materia de inspiración: «Y vino el desfile de ensueños y sombras./ Y fueron mujeres de rostros de estatua,/ Mujeres de rostros de estatuas de mármol, /¡Tan tristes, tan dulces, tan suaves, tan pálidas! ( (Darío, 1952, p. 35). Las mujeres- estatuas, piel de mármol, desconocen la sensibilidad, ya que son solo un objeto contemplativo para el estímulo creativo del poeta. De acuerdo con Gwen Kirkpatrick (2005), «la figura femenina es un objeto casi armónico con el lenguaje, profusamente decorado, distante y elusivo, a veces observado en secreto, mientras que el velo de misterio que la rodea es como el tejido melódico que recubre al verso» (p. 18). Con ello, la mujer y la galería de objetos aristocráticos que aparecen en el imaginario modernista son lo mismo, al igual que la mujer y el lenguaje, que en términos de su pedrería lujosa son equivalentes. En efecto, la mujer y la lengua poética se constituyen en los fetiches por antonomasia de los poetas, con la notoria diferencia de que el lenguaje puede hablar, mientras que la mujer es silenciada.

Junto a la visión objetual del modernismo conviven las imágenes de la «bella muerta», el tópico más poético de acuerdo con Poe, y la del «ángel del hogar» ${ }^{2}$. La primera reitera una concepción de mujer silenciada en el poema, representada por una voz patriarcal y, por consiguiente, musa del poeta a la que se exalta. Y la segunda, una imagen descorporeizada de la mujer, etérea, reina de la esfera doméstica carente de deseo y de su capacidad para expresarlo. En suma, de acuerdo con la crítica Ana Baeza:

el sujeto femenino se descorporaliza, difuminándose en una realidad ideal, inventada por el hablante para colocarla como el portal a través del que se accede a una dimensión de sí mismo, su propia alma y es en esta operación donde la mujer real desaparece, produciéndose la cosificación que la convierte en fetiche, es decir, algo que no tiene valor por sí mismo, sino por lo que representa (Baeza, 2012, p. 80).

2. La estudiosa Ana Baeza en su libro No ser más la bella muerta. Erotismo, sujeto y poesía en Delmira Agustini, Teresa Wilms Montt y Clara Lair incluyó en el imaginario modernista, además de las visiones señaladas, la femme fatale, la «mujer dormida», la «mujer fantasma», la «mujer-medusa». 
En relación con lo anterior, las mujeres no se constituyen como sujetos con agencia que puedan decir su subjetividad, sino que son habladas por otros, convirtiéndose así en sujetos subalternas, en tanto «el subalterno como femenino no puede ser escuchado o leído» (Spivak, 2003, p. 361) ${ }^{3}$. En este contexto, la poesía de mujeres se erige, de acuerdo con la lectura propuesta en este estudio, como un «habla talada», pues las poetas carecen de voz para expresar sus subjetividades, reiterando la historia patriarcal que solo las representa, las condena a la mudez y las fija conforme a la óptica masculinista. No obstante, las poetas se han apropiado estratégicamente de estas representaciones, pues de esta manera ingresan a la «ciudad letrada» y elaboran su propia voz. Así, ellas han recurrido a un «esencialismo estratégico», o sea, «el uso estratégico de un esencialismo positivista en un interés político escrupulosamente visible» (Spivak, citado por Lamas, 2007, p. 23) que les permite erigirse como portadoras de una voz y un discurso propios.

Si en el modernismo predominaba la representación de las mujeres como objetos suntuosos, los poetas también las han representado como naturaleza, pues esta última se analoga a distintos procesos vitales de las mujeres, particularmente, aquellos ligados a los ciclos, como el amamantamiento, la crianza de los hijos e hijas y la alimentación. La representación que ha identificado históricamente la mujer con la naturaleza — que las poetas apropian - permite establecer alianzas estratégicas, a partir de un esencialismo genérico positivizado. De este modo, las poetas configuran un nuevo locus enunciativo ${ }^{4}$ que las autoriza para politizar la naturaleza con el propósito de cuestionar el rol subordinado propio de un sistema sexo-genérico, que sitúa a los hombres en una jerarquía superior a las mujeres en cuanto sujetos ligados a la cultura y la razón. Así, la construcción de un espacio de habla nuevo en la poesía de mujeres se erige como:

[...] el medio privilegiado por el cual el sujeto subalterno desnaturaliza el orden autoritativo del símbolo (ancestral, mítico, memorioso), renegociando sus valores míticos en función del

3. Se entiende al sujeto subalterno de acuerdo con la lectura que realiza Roberto Hozven sobre los planteamientos decolonialistas indios: «La experiencia subalterna se relaciona con el hecho de habitar dos culturas a la manera de un encabalgamiento: una hegemónica, autorizadora, a la que de un modo u otro se desea pertenecer o ingresar, y otra subordinada, repetidora y marginal, a la que se pertenece por razones étnicas, religiosas, económicas o sociales que no se han escogido. La primera se asocia al poder y se inscribe en los círculos sociales privilegiados o prestigiosos, mientras que la segunda está privada de poder o alejada de los circuitos oficiales» (2001, p. 57).

4. En relación con la relevancia de este nuevo locus enunciativo, «Jardine observa que la diferencia entre los textos de la modernidad escritos por mujeres y los escritos por hombres no está en su “contenido", las diferencias están en su enunciación»(Genovese, 1998, p. 17). 
signo representativo del nuevo orden y situación comunitaria (secularizada, desmitificada) en la que el sujeto se encuentra inmerso... Son relatos subversivos cuyos códigos recurren a combinatorias prohibidas por la doxa (rumores de los subalternos iletrados) y por la otodoxia (el lenguaje dominante). Son heterodoxos, paradojales (Hozven, 2001, p. 66).

Así, las poetas, al apropiarse de la categoría naturaleza, desnaturalizan, desmitifican y deconstruyen el significado heredado por la tradición literaria, que se afinca en el dominio del hombre sobre ella entendida como salvaje y, por tanto, domesticable. A partir de ahí, las escritoras, en tanto sujetos subalternas, renegocian sus valores y elaboran nuevos relatos en las que es posible leer la metáfora fosilizada «mujer es igual a naturaleza» desde un paradigma que no desvaloriza su ligazón, sino por el contrario, se apodera de ella. Este «esencialismo estratégico» permite la asunción de una «subjetividad nómade» portadora de una conciencia «[que] es una forma de resistencia política a toda visión hegemónica y excluyente de la subjetividad» (Braidiotti, 2004, p. 216).

En consonancia con lo descrito, esta nueva manera de leer las textualidades de mujeres latinoamericanas implica el despliegue de una «visión analógica» (Salomone, 2006, p. 121) en la medida que hay una serie de correspondencias entre mujer y naturaleza que se explican por la existencia de ciertas prefiguraciones esencialistas que vinculan la sexualidad femenina a determinadas disposiciones fisiológicas y subjetivas, tales como la maternidad, crianza de niños, cuidado del hogar y mantenimiento del orden afectivo-sexual construido allí bajo el alero masculino. En esta línea, la «visión analógica»:

[...] puede aparecer en los discursos de mujeres mediante la apropiación acrítica de los significados con que el androcentrismo invistió la feminidad, desde otra perspectiva, podemos encontrar formulaciones analógicas en ciertos textos en los que las escritoras articulan discursos idealizados o utópicos para dar cuenta de visiones que difieren de las dominantes, desde una lógica otra de la racional y argumentativa, apelando para ello a formas trópicas diversas o al recurso de la ficcionalización (Salomone, 2006, p .122).

Sin embargo, y fundamentalmente, el poemario analizado titulado El jardín (1992), de Diana Bellessi, se caracteriza por el predominio de una «visión irónica», pues hay un ejercicio de cuestionamiento y deconstrucción de los modelos de la subjetividad femenina de origen patriarcal. En efecto, Bellessi y otras poetas recurrieron a la ironía, la parodia o la sátira para sus fines, vale decir, una adopción de «posición crítica como sujetos frente al mandato sociocultural del silencio y la subordinación». Esta visión, 
asimismo, pone en evidencia una «deconstrucción crítica» de algunos discursos de poder que excluyen a las mujeres del campo literario, de modo que en muchos casos se vincula a un posicionamiento feminista que exige igualdad de derechos tanto para varones como para mujeres (Salomone, 2006).

La apropiación del signo naturaleza se constituye, entonces, como una estrategia válida que muestra, y a la vez, revela la violencia ejercida por el orden androcéntrico tanto a mujeres como a la naturaleza en la medida que ambas se conciben como «objetos útiles» de los que el hombre se sirve y explota de acuerdo con sus necesidades y deseos. Por tal motivo, el hombre, como «sujeto civilizado», dociliza a la naturaleza, al objeto bárbaro: «Belleza bárbara / del matorral salvaje / donde se asoman las flores más pequeñas... Belleza / disciplinada donde se abren / las rosas pálidas y moteadas / o alguna reina / aislada, alada» (Bellessi, 2009, p. 442). Este proyecto patriarcal, colonialista y capitalista se basa en una «guerra» contra la biodiversidad que las mujeres protegen y resguardan, pues este «esencialismo estratégico» obedece no solo a una estética, sino a una política de género. En este sentido, las poetas, al asirse al esencialismo mujer-naturaleza, afirman «que la violación de la Tierra y la violación de las mujeres están estrechamente relacionadas: tanto desde el punto de vista metafórico, al determinar cosmovisiones, como material, al determinar la vida cotidiana de las mujeres» (Shiva, 2016, p. 19). Con ello, tanto el cuerpo biológico como el natural y el textual se aúnan y comparecen en un ritual femenino, el cual permite a las poetas expresar su subjetividad y denunciar la violación histórica con plena libertad en el poema. Así, el cuerpo tridimensional del poema invita al lector a ser escuchado ya no desde el rumor, propio del sujeto subalterno (Hozven, 2001), sino desde de un concierto de voces que no teme el escurrir de los movimientos de la lengua herbolaria y su sav(b)ia, pues se sitúa en el texto poético para dejar de convertirse en una «naturaleza muerta».

De acuerdo con lo anterior, el presente artículo problematiza y postula que el poemario El jardín (1992), de Diana Bellessi, elabora una retórica vegetal que evidencia particulares estrategias, a partir de las cuales se permite la apropiación de una categoría de naturaleza esencialista para cuestionar y desestabilizar su vínculo con lo femenil ${ }^{5}$ y

5. Neologismo utilizado por la poeta Gabriela Mistral ( «Me deja en estupor el escándalo que hacen algunos sobre la literatura femenina. ¿Tiene algo de sufragismo una canción de cuna? Pues esto es para 
lo íntimo. Así, la subjetividad femenina ingresa a órdenes catalogados como eminentemente masculinos $\mathrm{y}$, asimismo, se configura como sujeto que denuncia la violencia sexo-genérica, y a la vez propone una ecopolítica (Shiva, 1997). Esta retórica vegetal se caracteriza por la elaboración de metapoemas que homologan la escritura con el acto de sembrar, plantar o jardinear, y conjuntamente, por el despliegue de devenires vegetales de la enunciación. A través de ambas estrategias, se configura una subjetividad nómade y ecológica, la cual aboga por relaciones de convivencia y una ética del cuidado que cuestiona los regímenes patriarcales, colonialistas y capitalistas.

\section{El «arbustito meado» habla: el jardín como umbral y tránsito hacia la calle de la subjetividad nómade}

El poemario El jardín (1992), de Diana Bellessi, se enmarca en la producción y emergencia de una poesía publicada por un grupo de poetas mujeres en Argentina durante la década de los ochenta. Este grupo, diverso en estéticas y proyectos escriturales, convive con el mapa de la poesía argentina ochentera: neobarrosoneobarroco, objetivismo y neorromanticismo. No obstante, a pesar de su heterogeneidad, guarda en común una preocupación por politizar el signo «mujer»y «femenino». De esta manera, se erigen como productoras conscientes de un discurso generizado que polemiza, mediante un «discurso de doble voz» (Genovese, 1998, p. 33), con las representaciones masculinistas que de ellas elaboran sus pares varones. A partir de lo anterior, el texto-jardín ha sido leído por la crítica como:

[...] el despliegue de una imagen, la de un jardín que exige arduas preocupaciones a su autora. Imagen que alegoriza, a través de esos cuidados, el proceso de creación de un yo que tiene por sustento el rescate de una memoria individual, pero que es también social (Salomone, 2011, p. 12).

Asimismo, el texto-jardín se ha interpretado como un «espacio de aceptación, de íntima celebración de un sujeto femenino que a sí mismo se enuncia» (Genovese, 1998, p. 105). Desde el punto de vista del presente estudio, se concuerda con ambas lecturas y se hace énfasis en la segunda, pues este artículo se centra en determinar cómo la autora

mí la literatura femenil») y recuperado por la crítica Eliana Ortega en su texto Amada amante: discurso femenil de Gabriela Mistral, de 2016. 
produce la «subjetividad nómade», cuya «ecopolítica», a través de una «retórica vegetal», liga a las mujeres con la naturaleza.

En consecuencia, el poemario El jardín (1992), de la poeta argentina Diana Bellessi, se configura como un cuerpo textual, femenino y natural, que revela la apropiación de la categoría naturaleza, particularmente del jardín, para configurar una subjetividad históricamente violentada por su condición sexo-genérica. En este texto poético, la escritora recurrió a la estrategia poética que define la «retórica vegetal», a saber, el devenir vegetal de la voz poética. Con ello, no se busca una identificación o una mímesis con los elementos naturales, sino que mujer y naturaleza se convierten en una sola identidad, generándose así una «indiscernibilidad o indiferenciación tal que ya no quepa distinguirse de una mujer, de un animal o de una molécula» (Deleuze \& Guattari, 1988, p. 25). Esta estrategia retórica tensiona la categoría de identidad fija, pues el devenir implica un constante estar siendo que rompe las esencias fosilizadas para cuestionar los presupuestos patriarcales en los que la «categoría Mujer, pese a las diferencias que ciertamente existen entre las mujeres individuales, se [la] identifica claramente como una categoría signada por supuestos comunes culturalmente impuestas» (Braidotti, 2004, p. 12). Desde esta mirada, el devenir vegetal en este poemario politiza los «cuerpos naturales» y los dota de agencia para hablar desde locus enunciativos propios, ya que:

[...] se trata de una poesía que explora, en la figura de un sujeto imaginario femenino no unificado ni jerárquico, sino diseminado y plural, otra enunciación. Esa enunciación divergente toma a menudo el lugar del que se halla fuera de la ley. Ya sea de la ley del padre, de la ley dominante, de la ley consuetudinaria, entre otras: mujer, outsider, oprimido (Monteleone, 2009, p. 10).

En otras palabras, las «hablas taladas» se regeneran y se configuran como subjetividades nómades que han encontrado un territorio poético que les permite «golpea[r] contra el muro / Un espacio de resistencia / imposible de quebrar» (Bellessi, 2009, p. 458). En este caso, el jardín, en tanto espacio de resistencia, ${ }^{6}$ le permite a la voz poética abandonar el rol de escucha pasiva para transitar por espacios que le han sido

6. Al respecto, la crítica chilena Eliana Ortega señaló que en la poesía de Diana Bellessi «[...] las palabras resistencia y esperanza se reencuentran en cada uno de sus textos poéticos de una forma u otra. Resistencia a la mirada antropocéntrica y eurocéntrica, resistencia a la visión binaria del mundo y a las construcciones culturales occidentalizadas que excluyen al otro [...]» (Ortega, 2016, p. 128). 
prohibidos y hablar/cantar por sí misma, es decir, como sujeto, aunque no sin antes denunciar su condición de subalterna:

[...] En el pasillo oscuro veo como cantas. Los grandes cetáceos y los lobos en la noche helada cantan por mí. Soy reina frente a otra reina que quiso entregarte la corona no la cabeza. Mi reinado es de las locas, no tiene regalías tachada de la historia soy leyenda, marca impresentable mientras tú, fundas Roma (Bellesi, 1992, p. 439).

La voz enunciadora a través de una sintaxis fragmentaria y de encabalgamientos que formalizan a nivel temático la dicotomía naturaleza/cultura en tanto la primera cabalga a la segunda (Amorós, 1991, p. 33), revela la posición subalternizada de la mujer, pues no solo está confinada a la mudez y a escuchar la voz patriarcal, sino que también es hablada por otros: «cetáceos y los lobos / en la noche helada cantan / por mí». Con todo, la voz poética increpa al tú que la ha representado como reina, o sea, aquella figura que «es tan linda como tonta», ${ }^{7}$ que ha sido inscrita en el imaginario cultural. Ella deconstruyó este estereotipo al manifestar que entregó la corona, metonimia de la mujer-objeto ligada a las preocupaciones superficiales, para quedarse con la cabeza, metonimia de la razón; cualidad que le ha sido negada por el régimen patriarcal. En este sentido, su decir poético es el de la loca, pues es el espacio de la locura el que le permite configurarse como sujeto, dando cuenta con ello, como señaló María Moreno (2002), de que «A la cultura se entra loca y muerta o como El Hombre» (p. 161). Como fiel heredera de Gabriela Mistral $^{8}$, la subjetividad poética bellessiana a través del «reinado

7. Cita del cuento El árbol de la escritora chilena María Luisa Bombal. En el relato, la protagonista, Brígida, hija menor y retardada de un matrimonio, es confinada a casarse con un hombre mayor, quien la violenta con sus desprecios y la objetualiza como un «collar de pájaros». En este caso, puede apreciarse como la categoría de objeto y naturaleza son utilizadas por el marido para caracterizarla.

8. La poeta señaló como su gran maestra y poeta admirada a Gabriela Mistral: «Primero y sobre todo Gabriela Mistral y después, adoro a los modernistas. Me gustan mucho José Asunción Silva, el colombiano y por supuesto, José Martí, cuyas prosas adoro. Rubén Darío, quien es una enseñanza colosal todo tiempo. También la gente que nace con el Ultraísmo y que rompe con el Modernismo. En Argentina tengo grandes amores por Ricardo Molinari y por J. L. Ortiz, y por supuesto, con las que vienen después, como, por ejemplo, Amelia Biagioni, Alejandra Pizarnik, Olga Orozco y con todas las de mi generación hacia las más jóvenes» (André, citado por Ortega, 2016, p. 123). 
de las locas» obtiene licencias para expresar que la mujer ha sido «tachada de la historia» en tanto que «constituida por la locura, la diferencia no disminuye ahora a la sujeta de marras, sino que por el contrario es aquello que la dota de un ser y, a la vez, de un ser mejor»(Rojo, 2010, p. 349). La configuración en el poema del espacio de la locura se convierte en una estrategia válida o «treta del débil» (Ludmer, 1985, p. 34) para vehiculizar a través de la «materia alucinada ${ }^{9}$ un sistema desigual que sitúa a la mujer confinada al espacio de lo doméstico, mientras que el uno domina el ámbito de lo público («mientras tú, fundas Roma») y, en definitiva, la otra es invisibilizada en tanto «marca irrepresentable», que en términos de disposición gráfica del poema se manifiesta con el espacio en blanco, o sea, como encarnación de la nada. En el anterior fragmento, la voz poética cuestiona el lugar de lo privado al que ha sido relegada, pues ello implica el no acceso a la carta de ciudadanía que poseen los hombres. Por el contrario, el hombre no solo es ciudadano, sino que a la vez se erige como un conquistador y fundador de «territorios naturales»; en pocas palabras, como un sujeto portador de la letra que al nombrar ejerce su dominio y poder.

Precisamente de esta «marca irrepresentable» se quiere desasir al sujeto del jardín, al partir de la afirmación de que la voz poética ha sido exiliada de la historia, de modo que es ilegible y, por tanto, no accede a su autorrepresentación. Esta mujer-naturaleza solo ha sido representada como un «Territorio marcado por el escucha:/ arbustito meado» (Bellessi, 2009, p. 454). Este «arbustito meado, devenir vegetal de la voz, poetiza la violencia patriarcal y masculinista que ha recaído históricamente sobre las mujeres: la mujer es caracterizada como un «arbustito», situado en una jerarquía menor manifiesta en el uso del diminutivo, pero además está «meado», es decir, marcado por la ideología de la Ley del padre en tanto la marca es realizada con el falo y responde, por ende, a una representación patriarcalista. No obstante, la voz poética en su devenir arbusto (vegetal) transita por el jardín entendido como umbral hacia la calle y politiza el espacio, agenciando una subjetividad nómade en la que su propio nomadismo «es una forma intransitiva de devenir: marca una serie de transformaciones sin un producto final. Los sujetos nómades son cartografías vivientes del presente y crean mapas políticamente informados de su propia supervivencia» (Braidotti, 2004, p. 222). Desde esta mirada, la

9. Gabriela Mistral aseguró que para ella la poesía es «materia alucinada», es decir, el discurso poético se erige como un espacio de la locura que le permite a la poeta decir su subjetividad en tanto otra del régimen patriarcal. 
voz poética, al enunciar la violencia, testimonia su propio mapa de superviviente del «meado patriarcal» toda vez que cuestiona y problematiza las codificaciones genéricas. El devenir vegetal encara las categorías identitarias fijas y subvierte las normativas estáticas y unitarias del sistema binario occidental. En cambio, encarna una subjetividad móvil y compleja que valora la diferencia en y con la diversidad.

Por otra parte, el poemario también polemiza abiertamente con el discurso religioso, al referirse a Eva como la culpable del desajuste armónico del Paraíso o el Jardín del Edén: «[...] Eva paga caro la ruptura del pacto / Quiere saber / Expulsada del Edén / ve el horror / y no la estética graciosa de las formas»(Bellessi, 2009, p. 452). La voz poética, a través de una «visión irónica», expresa cómo Eva, la mujer, en su afán de conocer/saber, es castigada y expulsada del Jardín, de tal modo que esa búsqueda del conocimiento encarna el «horror»e impide no ver la «estética graciosa de las formas» fijas pintadas/escritas por la mano falogocéntrica. Con ello, la mujer se condenó al silencio y, por ende, a una posición subordinada que le «impide[n] a [su] cuerpo / flamear / por los pasillos abiertos del verde» (Bellessi, 2009, p. 454). De ahí que desde la herida la subjetividad busque instalar su voz y crear su propio jardín: «derrapar de la araña / sobre las costras, las cortezas» (Bellessi, 2009, p. 454). De esta manera, la poeta vincula a la mujer con Aracné, tejedora griega que desafió las leyes del Olimpo, particularmente, a Atenea, quien la condena a vivir como araña debido a su actitud de engreimiento. Del mismo modo, la mujer se rebela frente al orden androcéntrico recurriendo a comportamientos «contrarios a los cánones tradicionales de la sociedad», según la definición de la palabra derrapar, proveída por el DLE. Así, la poeta construye en términos de Nancy Miller una «aracnología» ${ }^{10}$, vale decir, una textualidad que «consiste en leer todo texto contra la metáfora textil de lo indiferenciado; los textos producidos por mujeres son como telarañas o lugar donde la araña, la escritora metafóricamente, teje su tela y permanece conectada físicamente con ella, no

10. El motivo de la mujer-tejedora proveniente desde el mito de Aracné, pasando por la Penélope de La Odisea, también se puede apreciar en la poesía latinoamericana. Baste citar dos ejemplos. El primer poema Pavana para una infanta difunta, de la poeta argentina Olga Orozco (1985), del cual se cita el siguiente fragmento: «Pequeña centinela, /caes una vez más por la ranura de la noche / sin más armas que los ojos abiertos y el terror / contra los invasores insolubles en el papel en blanco. / Ellos eran legión. / Legión encarnizada era su nombre y se multiplicaban a medida que tú destejías hasta el último hilván, / arrinconándote contra las telarañas voraces de la nada...» (fragmento). El segundo, Llave testigo, de la poeta chilena Alejandra del Río (2015), del cual se extrajo el siguiente fragmento: «Seguí el paso del hilo / tejiendo una tela invisible / a hablar aprendería con los años / yo sobreviví al hacha-silencio / Contener ese aliento es mi cometido». 
desaparece»(Genovese, 1998, p. 29). La voz del poema, por tanto, teje su propia tela, se autorrepresenta en «las lunas de la locura / [donde] recibió reino de verdad» ${ }^{11}$ (Mistral, 2010, p. 25). Dicho de otro modo, mediante la poesía logra hablar y esbozar una crítica a la historia que ha tachado a la mujer en tanto se la ha concebido como objeto: «¿o acaso / ella el objeto, inmóvil / y preciso / y aquí el sujeto en deseo / de disolver su trato?»(Bellessi, 2009, p. 477). En efecto, la locura se convierte en un terreno productivo, una estrategia que permite el desplazamiento metonímico de objeto a sujeto; en otras palabras, de un sujeto pasivo y subalternizado a otro más activo y con agencia.

Mientras tanto, la voz enunciadora del poemario abandona el traje de sujeto subalterna al apropiarse del espacio del jardín, aquel lugar en el que la diferencia no es sinónimo de otredad, sino de comunión y armonía. En el poemario, la mujer se alza en contra del sistema patriarcal que acentúa la diferencia para convertir al otro en enemigo: «[...] El otro no es / el enemigo dice / la leyenda desde siempre / y el yo desoye [...]» (Bellessi, 2009, p. 495). La enunciadora aboga, pues, por un espacio ecológico y biodiverso, en el que todas las especies convivan de manera comunitaria, señalando con ello, que «La diversidad está, en muchos aspectos, en la base de la política de las mujeres y de la política ecológica. La política de género es en gran parte una política de la diferencia» (Shiva, 1998, p. 14). En consecuencia, la voz contraria, al tachar al otro como enemigo - en términos que responden a una retórica de carácter bélico- prefiere afirmarse en la otredad para valorar y reconocer la diferencia. En otras palabras, defiende la diferencia en la diversidad desde un marco afirmativo, polemizando con las políticas genéricas excluyentes que entienden la diferencia como un revés negativo.

En este contexto, la subjetividad poética consciente de las diferencias aboga por la obliteración de la alteridad inherente del sistema falogocéntrico y binario que traza una línea entre aquello que es entendido como objeto y, por tanto, digno de ser erradicado, y aquel que se erige como sujeto:

Belleza de la diferencia. Sólo un sistema binario podría condenar de hereje esta contradicción. Belleza del sujeto contra la ley y belleza de la especie cuyo fin pareciera aferrarse a la vida y reproducir lo mismo bajo la ley

11. Versos correspondientes al poema de Gabriela Mistral de: «Todas íbamos a ser reinas» (Tala) en el que se aprecia un rasgo metapoético de su escritura: la locura como motivo recurrente en su obra se articula como espacio productivo para la escritura. 
Especie y sujeto no obstante, se deben entre sí, se sostienen con sus propias hazañas y sabiduría parece, radica en aquella contradicción. Ambos un tanto estúpidos y ambos de tal saber y belleza (Bellessi, 2009, p. 490).

En este caso, la voz poética defiende una visión del mundo primigenia y premoderna en la que se conviva con las diferencias en pos de relaciones de interdependencia y gratuidad, pues es consciente de que «La biodiversidad ha sido siempre un recurso comunitario local»(Shiva, 1997, p. 90). De esta manera, se discuten las ideologías antropocéntricas y androcéntricas que elaboran divisiones entre sujeto y especie y entre hombres y mujeres. Estas dicotomías que ponen en el centro al hombre son negadas para afirmar la «belleza de la diferencia».

Frente a dicho aspecto, Bellessi planteó que las diferencias sexo-genéricas que sitúan a las mujeres como las otras del sistema patriarcal o, dicho de otro modo, como sujetos subalternos, son representadas como pertenecientes a otra especie: la vegetal. Esta diferenciación connota una separación que posiciona a las mujeres en un espacio liminar que les permite transitar como «subjetividades nómades» (Braidotti, 2004, p. 216), toda vez que se salen de la especie y abandonan la identidad fija que se les ha impuesto. En este contexto, la voz a pesar de la violencia del «meado» patriarcal aboga por una pedagogía feminista nómade y ecológica, en la que las diferencias genéricas no son motivo de discordias y violencias, sino por el contrario, una oportunidad para convivir en la «contradicción», pues «Especie y sujeto no obstante, se deben entre sí». De esta manera, la voz poética, en su constante transitar, encarna un nomadismo feminista que tensiona y cuestiona el imaginario patriarcal, en el que las mujeres constituyen subjetividades homogéneas para, al contrario de lo que se cree, «favorece[r] la multiplicidad, la complejidad, el antiesencialismo, el antirracismo y las coaliciones ecológicas» (Braidotti, 2004, p. 222). En este contexto, el sistema binario que sitúa a la mujer en el nivel inferior de la jerarquía se pretende deconstruir, pues este es regido por la ley del padre, que expulsa a la mujer fuera del orden simbólico, en tanto considera que sus prácticas no son racionales: «Fuera de sistemas la fe / de una mujer se vuelve / habla de niña tonta» (Bellessi, 2009, p. 493). En estos versos, las relaciones de correspondencias y la fe en una medicina premoderna se convierten en un habla tonta, o bien, en un no-lenguaje, en tanto obedece a regímenes ligados a la magia, esto es, a una «visión analógica» y no a la razón basada en un saber cientificista. Así, el espacio del 
jardín, apropiado por la subjetividad poética, recupera esta lengua herbolaria, no solo porque a través de ella se permite decir su experiencia, sino porque además se erige como un sujeto con un saber/poder de otro:

\author{
Desmalezo un canterito y planto: orégano, \\ perejil, cilantro. La peperina y un macizo \\ de flores afrutillado. No ser la narradora \\ sino la diosa fuera del lenguaje. Caer en la \\ tentación de homologar, como belleza el reino \\ de la necesidad. ¿Necesidad de qué? De tentar \\ con las formas un concierto que \\ exprese gratuidad: desde la leyenda (Bellessi, 2009, p. 484).
}

En este fragmento, la sujeto en el jardín ya no es hablada por la voz patriarcal, sino que, al apropiarse del espacio, se convierte en diosa fuera del lenguaje, fuera del orden simbólico, propio de la ley del padre que rechaza las voces hegemónicas, de ahí que no desea ser la «narradora» o la voz oficial. Por el contrario, al situarse fuera del lenguaje, en este espacio de lo íntimo y lo femenil ligado a lo doméstico, resemantiza estos significados al otorgar al conocimiento herbolario un poder femenino transmitido a través de la «leyenda oral», encarnada por las mujeres que comparten la «gratuidad» con sus iguales. De este modo, la leyenda, su cetro de diosa, aquel discurso marginal, transmitido de boca en boca, a saber, reino de la oralidad, se busca que conviva homólogamente con la Historia, con aquel discurso letrado y oficial: «¿Vive en mí / tu dicha indistinta / que deseo y temo, falta de sentido que / completa el sentido fuera / del discurso y reina / no obstante en el jardín?»(Bellessi, 2009, p. 463). Así, la voz enunciadora vive la experiencia subalterna con deseos de imitar a la voz patriarcal, que porta la palabra y a la vez se aleja de esta, al reinar en un espacio que le es propio y donde le es posible el despliegue de su lengua herbolaria y su nomadismo. En consecuencia, esa voz aún cree que ambos discursos pueden convivir de modo ecológico, configurando con ello un concierto de voces en la que ninguna resalte sobre las otras, sino que se complementen para lograr asir la armonía.

La voz poética, situada fuera del lenguaje por cuanto se adhiere a un lenguaje otro basado en la fe y en leyenda desoída, apostrofa a la madre para que la salvaguarde de la violencia patriarcal que no escucha el murmullo de las hojas, de los tallos que hablan: «Oh madre, sálvame / de la cháchara y el basureo sálvame» (Bellessi, 2009, pp. 14-15). El jardín se convierte entonces en un lugar apto para hablar, pues es allí —en el lugar de 
las mujeres - donde su voz es escuchada desde un emplazamiento que no corresponde a la ley del padre, sino a un estadio anterior y primigenio, o sea, el de la madre que la faculta para denunciar la «meada» de la violencia patriarcal:

Qué quiere el poder. Ni siquiera

al sujeto que lo tiene

quiere

ser el instante completo

que abolió la duración

y la diferencia. Igual así

autónomo, eterno. La madre, en cambio

desea

caminar por la pradera entre sus hijos

aceptar la muerte y poner

su heredad en la diferencia. Sueña

y el sueño está hecho del detalle.

Lo que hicimos juntos, lo no hecho

se disuelve entre sus hijos (Bellessi, 2009, pp. 505-506).

En el caso anterior, la madre, a diferencia del padre, no traza líneas separatistas, no busca la omnipresencia, ni «ser el instante completo», ni aboga por la homogeneidad, sino por el respeto a la «heredad en la diferencia», un respeto a la biodiversidad, que reconoce su aporte y no es concebida como obstáculo. En efecto, la madre promueve un estilo de vida que se sustenta en la microscopía del mundo, es decir, en los detalles y en la heterogeneidad, de manera que polemiza con las concepciones patriarcales uniformadoras y totalizantes. Conjuntamente, promueve la utopía, propia de la «visión analógica», que descansa en la idea de la comunión, la contigüidad y vínculos de interdependencia genérica. En concreto, la madre primigenia configura otro orden, basado en relaciones de correspondencias y reciprocidad, un orden con el que la voz poética se identifica: «Si todo orden / es aleatorio, me sujeto / a éste, aunque precario / eterno en mi mirada: / Belleza bárbara / del matorral salvaje» (Bellessi, 2009, p. 442). Así, la madre, al ampararse en el orden de la madre primigenia se sujeta, es decir, se erige como sujeto y deja de convertirse en objeto, que, por improductivo, se desecha. Opta por un orden aleatorio que escapa al razonamiento, y que, por ende, se concibe como precario en tanto responde a un régimen «mágico» que ve la belleza del «matorral salvaje» donde la ideología patriarcal ve una oportunidad para domesticar, docilizar y explotar la naturaleza. 
Entretanto, la configuración de las subjetividades sobre la base de sus diferencias desde una óptica negativa implica una separación, que al no ser apropiada estratégicamente por las mujeres es utilizada por el régimen patriarcal como una tecnología biopolítica que imprime en los cuerpos su poder:

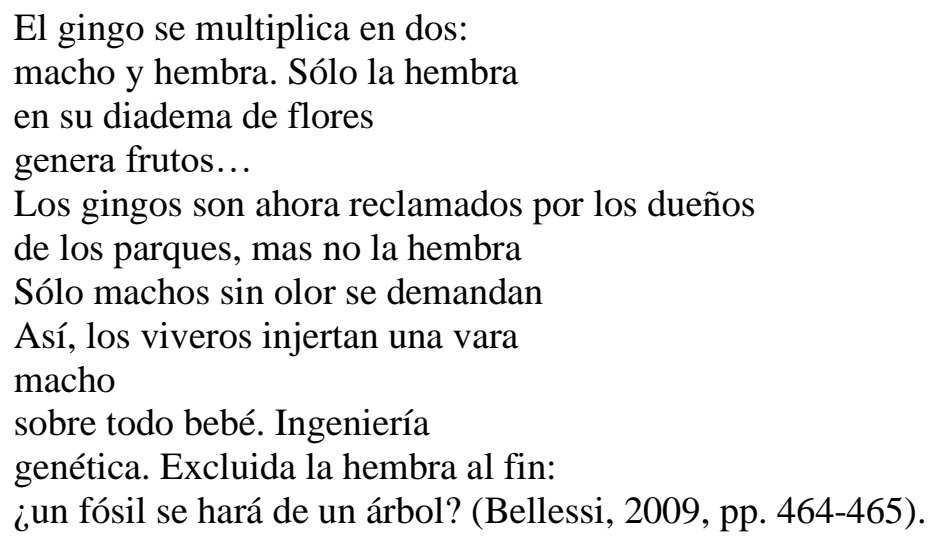

En este punto, la enunciadora, a través del desplazamiento metafórico, poetiza las consecuencias de un sistema sexo-genérico binario, que traza una línea divisoria entre hombres y mujeres, así como entre sus respectivas funciones o roles sociales, desdeñando, por tanto, la diversidad de la diferencia: «Belleza de la diferencia/Sólo un sistema/binario podría condenar de hereje/ esta contradicción» (Bellessi, 2009, p. 490). Con ello, se cuestiona la posición subalterna de la mujer, pues en relación con el hombre se la considera molesta (¿maleza?), de modo que queda «excluida la hembra al fin» (Bellessi, 2009, p. 464). En estas circunstancias, la diferencia es utilizada por el patriarcado para enfatizar el poder que unos cuerpos ejercen sobre otros. De este modo, la voz poética, a través del devenir vegetal, plantea en los versos anteriores una reflexión sobre las implicancias de las tecnologías biopolíticas en lo que concierne a las mujeres. De acuerdo con ella, se excluye a las gingo hembras por ser generadoras de frutos, mientras que se prefiere a los machos que apenas expelen aroma a través de mecanismos de la ingeniería biogenética. Ello connota el coste que implica para la sociedad la reproducción de mujeres, en contraste con los hombres que son, principalmente, solo generadores de una producción que se alía con la colonización capitalista de las especies. Además, la voz polemiza con estos mecanismos biopolíticos, basados en una traza dicotómica de los géneros reproducción/producción, en tanto esta «se convierte en un instrumento del patriarcado capitalista para colonizar la regeneración de las plantas y de los seres humanos» (Shiva, 1997, p. 67). 
Entre otros aspectos, el agenciamiento ecopolítico de la subjetividad nómade presente en el poemario es expresada a través de un posicionamiento crítico sobre las ideologías antropocéntricas y androcéntricas, que promueven divisiones binarias y excluyentes de subjetividad. En concreto, la autora agenció la voz poética del texto al establecer una alianza entre mujeres y naturaleza, en tanto ambas son objetos de una ideología patriarcal que las violenta y destruye. En palabras de la teórica ecofeminista Alicia Puleo (2005): «Las mujeres estamos en una posición particular con respecto a la Naturaleza. Hemos sido adscritas (y seguimos siéndolo) de alguna manera a ella como al ámbito de lo inferior y subhumano» (p. 202). De este modo, el «esencialismo estratégico» adoptado politiza la naturaleza para generar un lugar de enunciación cuestionador de la explotación de la que son víctimas las mujeres.

En línea con lo anterior, la ecopolítica que asume la voz poética aboga por la afirmación de la diferencia y está en contra de las lógicas dominantes y totalizadoras del patriarcado neocolonialista y neoliberal. Sin embargo, su énfasis está en la valorización de la riqueza de la diversidad: «Al tropismo de muerte sólo / la diversidad se opone» (Bellessi, 2009, p. 479). Ello implica una ética del cuidado que aboga por la protección de las especies y el despertar de una conciencia que no debe olvidar que un mundo sostenible solo es potencialmente factible si se entiende que el dilapidar de los recursos naturales — con un afán meramente extractivista - no permitirá a las generaciones futuras disfrutar de ellos:

Ahora que miro el despertar

Si olvidamos el jardín, no habrá dulces de durazno

No habrá niños en la humana calidad de nuestras manos

Puestos a soñar con la tierra pelambre (Bellessi, 2009, p. 490).

En este caso, puede apreciarse que el despertar de la modorra veraniega permite no olvidar que la existencia y sobrevivencia de los seres humanos se basa en vínculos de interdependencia con las demás especies, de ahí que la voz poética asuma una visión ecopolítica y defienda todas las formas de vida: «Que las formas de la vida / no perezcan /el ciruelo y la glicina / suave alfombra de musgo» (Bellessi, 2009, p. 477). La conciencia ecológica sostiene, por tanto, una «ecojusticia intergeneracional» (Puleo, 2005 , p. 16) que implica heredar a las generaciones venideras los «dulces de durazno» provenientes del jardín. 
Entre otro de los asuntos de análisis, la alianza inter-especie entre las mujeres y la naturaleza surge cuando se asume que a las mujeres se las ha naturalizado y a la naturaleza se la ha feminizado, esencialismos patriarcales, que positivizados encarnan una lucha y reconocimiento políticos encarnados en «éticas ecológicas que reconocen un valor inherente a otros seres, además de los humanos, o al ecosistema en su conjunto [...]» (Puleo, 2005, p. 16). Así, la voz del poema, siguiendo los planteamientos anteriores, se hermana con el árbol, pues se reconoce en él cuando camina:

Caminé en la primavera temprana por los senderillos de las islas viendo a cada árbol encender su gracia definitiva. Detenerse en el detalle precioso de la forma. Yo su hermana ¿con mi corona de zarcillos propios?

[...] Sabiduría

en la diversidad y belleza en la repetición ¿He ahí la invisible costura que nos separa? Una identidad hallada en la obediencia, ¿o acaso sueñan los árboles con el jardín salvaje donde al orden que los concibe dueños de sí alteran?

Para el mundo vegetal ¿hay leyenda? (Bellessi, 2009, p. 482).

En este punto, la voz, desde una mirada enfocada en lo mínimo, en la microscopía de los detalles, y a su vez ajena a escopías totalizantes, advierte el valor de la (bio)diversidad y la belleza de los ciclos naturales que comportan una sabiduría particular. El reconocimiento y la hermandad entre la voz y el árbol implica asumir «la costura invisible» de la ideología patriarcal androcéntrica y antropocéntrica, que establece límites y separaciones entre diversas identidades, con el fin de excluirlas a través de rígidas narrativas obedientes. En cambio, la voz poética ve en la «belleza [de] la repetición»—-de los ciclos del árbol— su propio cuerpo, pues al igual que él, ella también los experimenta. Por último, polemiza, a través de una pregunta retórica, con los imperativos identitarios, a fin de enunciar una salida mediante la alteración del «jardín salvaje», espacio docilizado y ordenado, en el que se hermanan plantas y mujeres para desarmar el yugo de los «dueños» que las conciben como propiedad. 


\section{3. «No sé escribir. Hago Jardines»: jardines ${ }^{12}$ metapoéticos en la poesía de Diana}

\section{Bellessi}

La escritora chilena Guadalupe Santa Cruz en el libro Ojo líquido (2011) señaló que no sabe escribir, sino que hace jardines. Poetas como Diana Bellessi, Violeta Parra, Gabriela Mistral, Marosa di Giorgio y Elvira Hernández comulgan con esta concepción de la literatura. Las acciones como sembrar, jardinear o plantar son equivalentes a los actos de escribir, de ahí que, por ejemplo, provenga la metáfora podar versos, propia del quehacer poético. Debido a lo anterior, no es raro apreciar en sus producciones poéticas huertos, jardines o macetas signados por una marca sexo-genérica femenina. Un ejemplo paradigmático en la poesía latinoamericana es el poema La jardinera, de Violeta Parra, ${ }^{13}$ quien a través del tropo del jardín poetiza la escritura poética del desamor y su consecuente catarsis, es decir, concibe el acto de escribir como sanación: «Para olvidarme de ti / voy a cultivar la tierra, /en ella espero encontrar / remedio para mis penas [...] Cogollo de toronjil, / cuando me aumenten las penas, / las flores de mi jardín / han de ser mis enfermeras [...]» (Parra, 2016, pp. 64-65). Así, palabra y planta son equivalentes, de la misma manera que escribir y plantar, pues ambas acciones sanan.

Huerto o jardín, entonces, se convierten en tropos privilegiados por las poetas para significar la escritura de mujeres. Escritoras como Mistral, Bellessi, Parra, Hernández, entre otras, se apropiaron del esencialismo mujer-naturaleza para erigirse como escritoras-productoras de un discurso poético móvil que da cuenta de un «curioso vaivén que oscila entre el terror, el respeto y una denuncia, una toma de posesión de

12. El jardín se convierte en un espacio que permite cuestionar los roles de género. Así, por ejemplo, la poeta Emily Dickinson a través de este lugar criticó la imposibilidad de la mujer de cruzar el umbral del espacio privado «exclusivamente femenino» a uno público «exclusivamente masculino»: «Al otro lado de la verja, /crecen fresas. / Yo podría saltar al otro lado de la verja, /si lo intentara, lo sé. ¡Son tan ricas las fresas...! / Pero si manchara mi Delantal, /Dios, seguramente, me reprendería. / Santo Cielo, me imagino que si Él fuera un Muchacho, / si pudiera saltaría!» (2013, pp. 185-186). En este caso, la voz poética señala que tiene la certeza de que si lo intentara podría cruzarlo, esto es, no por falta de capacidades, sino por la negación y los efectos de la reprimenda por realizar una «osadía» de ese tipo.

13. Para Violeta Parra, los poemas surgen «cuando han de florear los vocablos» (2016, p. 147), es decir, su canto nace del trabajo de la jardinera/hortelana quien ha sembrado/plantado y recibe el fruto de su jardín. De esta forma, el acto de poetizar se metaforiza en el acto de sembrar, enterrar o «desentierrar» la tierra. Es esta la que le permite a la jardinera obtener de ella campos sembrados de dolor, fe o esperanza, pues se cosecha, finalmente, lo sembrado/escrito por la sembradora/poeta: «Igual que jardín de flores / se ven los campos sembra'os, / de versos tan delica'os / que son perfeutos primores; ellos cantan los dolores, / llenos de fe y esperanza» (2016, p. 150). 
saberes ancestrales que se enclavan en ellas con un rigor extremo, con una fuerza que la convierte en depósito de sus formas» (Brito, 1998, p. 10). Las poetas, al ser sujetos de su propio discurso, dejan de ser la flor laureada que se le concede al poeta como objeto de posesión para elaborar y configurar su propia subjetividad. En tanto jardineras conocen los secretos de la naturaleza, de modo que son poseedoras de un saber «otro» que las faculta para ingresar al campo de la escritura. Las poetas no necesitan situarse en el dominio de la esfera pública para cantar, sino que se ubican estratégicamente en el espacio de lo privado, de modo que el jardín se politiza, es decir, se convierte en una zona o territorio desde el cual pueden enunciar un discurso poético.

El jardín permite entonces a la otra hablar desde un espacio marginal, pero movedizo en tanto umbral, esto es, un lugar de tránsito hacia un orden catalogado históricamente como masculino: la letra. Con lo anterior, las poetas se autorizan para «publicar lo privado: hacerlo objeto de atención, estetizarlo, hacerlo advenir campo de las preocupaciones políticas...» (Brito, 1998, p. 13). El lugar del jardín, por consiguiente, se erige como un emplazamiento de lucha y resistencia, una zona en la que las mujeres se liberan y se autoconfiguran, se desean y protestan por un sistema sexo-genérico que las excluye. Por lo tanto, el jardín poetizado por las escritoras deja el murmullo de lo íntimo para transitar a la calle desde el aullido.

En este mismo sentido, la poeta Diana Bellessi recurrió al jardín en su poemario homónimo (1992) para elaborar su metapoética y denunciar la condición histórica de «hablas taladas» de las mujeres:

He construido un jardín como quien hace

los gestos correctos en lugar errado.

Errado, no de error, sino de lugar otro, como hablar con el reflejo del espejo

y no con quien se mira en él (Bellessi, 2009, p. 469).

Así, el jardín, en tanto espacio no asignado para el ejercicio poético de la mujer, se convierte en un espacio otro y, por ende, marginal. No obstante, la subjetividad poética se ubica estratégicamente en él para «realizar los gestos correctos» (escritura) en un lugar culturalmente «errado» (campo literario patriarcal) de acuerdo con la historia de la literatura que ha invisibilizado y obliterado a las mujeres de un canon mayoritariamente masculino. Por tanto, el jardín es el locus enunciativo que permite el ingreso a la «ciudad letrada» de la voz poética, aun cuando, su gesto (la escritura) sea como hablar 
con los reflejos de un espejo, o lo que es lo mismo, con la sombra y no con los sujetos que producen la escritura.

El lugar para enunciar se ha encontrado, de modo que «Ahora la lengua puede desatarse para hablar. / Ella que nunca pudo el escalpelo del horror / provista de herramientas para hacer, maravillo de ominoso» (Bellessi, 2009, p. 469). El habla talada, por tanto, se regenera; ya no es mero reflejo de un espejo, sino un sujeto que sublima mediante la escritura poética lo reprimido. La voz poética expresa que «Tener un jardín es dejarse tener por él y su / eterno movimiento de partida...» (Bellessi, 2009, p. 469), de manera que mujer y escritura se acoplan. La poeta/jardinera, además, otorga el nacimiento, poda o da muerte a un poema: «Flores, semillas y plantas mueren para siempre o se renuevan. Hay / poda y hay movimientos [...]», el jardín «demanda su mano que recorte y modifique / la tierra desnuda, dada vuelta en los canteros / bajo la noche helada» (Bellessi, 2009, p. 469). Luego, la escritura de mujeres desde y a través del jardín busca mostrar la condición históricamente desierta del ingreso de estas al campo de la escritura: «Pero hacer gestos correctos /en el lugar errado / disuelve la ecuación, descubre el páramo» (Bellessi, 2009, p. 469). Por eso, la subjetividad poética, al denunciar la condición yerma y estéril del espacio de la escritura poética para mujeres, simultáneamente, revela la posibilidad de regeneración de un territorio deforestado para ellas. La maleza porfía y florece: canta y se desliga de este mandato para situarse en el «estar mayestático de / la dicha. Alfombra / de orquídeas diminutas / sobre el pasto florecen / antes que la máquina / cortadora de césped arrase ¿aprendieron? (Bellessi, 2009, p. 471). En este caso, la máquina cortadora, en su construcción fálica, connota la violencia ejercida por el patriarcado hacia las mujeres, de ahí que la voz poética impela a sus destinatarias al goce de las «flores» de su jardín (la escritura prohibida).

Finalmente, el jardín, como una metáfora de la escritura poética de mujeres, no solo descubre su condición estéril para las poetas, sino que a través del devenir vegetal de las voces señala la posibilidad de estas de ser violentadas y matadas, «antes que la máquina / cortadora de césped arrase»(Bellessi, 2009, p. 471). Debido a lo anterior, la voz poética se hermana con los árboles, ambos explotados y violentados: «Lo he plantado en esta primavera / ¿Qué sé de su sentir / en la noche helada donde el viento doblega? / Lábil el tronco joven se quiebra / Lo han quebrado / y lloro de rodillas ante el muñón / y 
la copa desvanecida. Lloro sosteniéndolo en mis manos/donde se vuelve de plata, no de polvo su corteza» (Bellessi, 2009, p. 481). En este caso, la herida del árbol también le pertenece, ya que sostenerlo en sus manos significa sostenerse a ella misma, sujetarse en sus raíces, en un orden primigenio que le permite nombrar, decir y decirse: «Ante la azucarada / copita de menta, la madre, la materia, le otorga los nombres / para nombrar la primavera. Le otorga la ley / que los separa / dándoles existencia» (Bellessi, 2009, p. 481). De esta manera, el llanto no es personal, sino que es genérico y social.

\section{A modo de conclusión}

El ingreso de las poetas al campo literario fue un acto de desacato y transgresión, toda vez que implicó a través de distintas «tretas del débil» (Ludmer, 1985) obedecer, pero también romper con las estructuras y leyes del sistema hegemónico patriarcal. Su entrada a la «ciudad letrada» no fue posible si no mediante la apropiación de representaciones sobre las mujeres que corresponden a imaginarios patriarcales. La mujer como naturaleza constituye una de estas imágenes que las poetas utilizan para poder situarse como poetas y enunciarse desde un locus propio.

Por tal motivo, la poeta argentina Diana Bellessi en su poemario El jardín (1992), recurrió al «esencialismo estratégico», el cual vincula mujer con naturaleza para desde allí hablar y generar un discurso poético crítico que cuestiona y desestabiliza los presupuestos patriarcales. En este texto, la poeta elaboró una retórica vegetal mediante las estrategias del devenir vegetal de la voz poética, así como metapoemas que homologan las acciones del plantar y jardinear como el acto escritural; denuncia a su vez la violencia sexo-genérica que se inscribe sobre sus cuerpos y, asimismo, configura una subjetividad nómade ecológica que promueve la convivencia, el respeto y la comunión entre los sujetos. Ello conduce a una ética del cuidado que abandona la concepción de la naturaleza como objeto domesticable y explotable, es decir, mirada desde una óptica colonialista y capitalista. Y, simultáneamente, aboga por la valorización de los saberes y conocimientos ligados a la naturaleza que escapan a horizontes racionales y cientificistas. 


\section{Referencias bibliográficas}

1. Amorós, C. (1991). Hacia una crítica de la razón patriarcal. Madrid: Anthropos.

2. Baeza, A. (2012). No ser más la bella muerta. Erotismo, sujeto y poesía en Delmira Agustini, Teresa Wilms Montt y Clara Lair. Santiago: Ediciones USACH.

3. Bellessi, D. (2009) «El jardín». Tener lo que se tiene. Poesía reunida. Buenos Aires: Adriana Hidalgo Editora.

4. Briadotti, R. (1998). Feminismo, diferencia sexual y subjetividad nómade (2004). Barcelona: Gedisa.

5. Brito, E. (1998). «Prólogo». Antología de poetas chilenas. Santiago: Dolmen.

6. Darío, R. (1952). Poesía. libros poéticos completos y antología de la obra dispersa. México, Fondo de Cultura Económica.

7. Deleuze, G. \& Félix G. (1988). Mil mesetas: capitalismo y esquizofrenia (1988). Valencia: Pre-Textos.

8. Del Río, A. (2015). Llaves del pensamiento cautivo. Santiago: Garceta.

9. Dickinson, E. (2013). Poesía completa. (Trad. Enrique Goicolea). Madrid: Amargord. 10. Genovese, A. (1998). La doble voz. Poetas argentinas contemporáneas. Buenos Aires: Biblos.

11. Hozven, R. (2001). Convergencias y divergencias en torno al concepto de subalternidad. Taller de Letras, 29, 55-68.

12. Kirkpatrick, G. (2005). Disonancias del modernismo. Buenos Aires: Libros del Rojas.

13. Lamas, M. (2007). Feminismo. Transmisiones y retransmisiones. México: Penguin Random House.

14. Ludmer, J. (1985). «Tretas del débil». En P. González \& E. Ortega (Eds.). La sartén por el mango. Puerto Rico: Editorial Huracán.

15. Mies, M. \& Vandana S. (2016). «Prefacio a la nueva edición». Ecofeminismo. Teoría, crítica y perspectiva. Barcelona: Icaria.

16. Mies, M. \& Vandana, S. (1998). La praxis del ecofeminismo: biotecnología, consumo y reproducción. Barcelona: Icaria. 
17. Monteleone, J. (2009). La poesía como tierra sin mal: habla, mirada, gracia y donación. Prólogo a Bellessi, Diana. Tener lo que se tiene. Poesía reunida. Buenos Aires: Adriana Hidalgo Editora.

18. Moreno, M. (2002). El fin del sexo y otras mentiras. Buenos Aires: Editorial Sudamericana.

19. Orozco, O. (1985). Obra poética. Buenos Aires: Corregidor.

20. Ortega, E. (2016). Habitar el paisaje: tres poetas sudamericanas: Bellessi, Fariña, Varela (2016). Santiago de Chile, Cuarto Propio.

21. Parra, V. (2016). Violeta Parra. Poesía. Valparaíso: Editorial Universidad de Valparaíso.

22. Salomone, A. (2006). Alfonsina Storni: mujeres, modernidad y literatura. Buenos Aires: Corregidor.

23. Salomone, A. (2011) Poesía, memoria y comunidad nacional Chile Argentina en posdictadura. Revista Sociedad \& Equidad, 1 ,1-22.

24. Puleo, A. (2011). Ecofeminismo. Para otro mundo posible. Valencia: PUV.

25. Rojo, G. (2010). «Prólogo». Gabriela Mistral. Antología esencial. Madrid: Biblioteca Nueva.

26. Santa Cruz, G. (2011). Ojo líquido. Santiago: Palinodia.

27. Shiva, V. (1997). Biopiratería. El saqueo de la naturaleza y el conocimiento. Madrid: Icaria.

28. Spivak, G. (2003). ¿Puede hablar el sujeto subalterno? Nota introductoria de Santiago Giraldo. Revista Colombiana de Antropología, 39, 1-69. 